\title{
STUDY OF FIRE GROWTH BEHAVIOR IN A RESIDENTIAL APARTMENT USING FIRE DYNAMIC SIMULATOR
}

\author{
Fahim Shahriar Sakib, Riazuddin Ahmed and Easir A Khan* \\ Department of Chemical Engineering, Bangladesh University of Engineering \& Technology, Dhaka- \\ 1000, Bangladesh
}

\begin{abstract}
Fire accidents are very frequent and a major issue in Bangladesh in recent times. In this paper fire growth behavior in an apartment building is studied through a numerical analysis using Fire Dynamic Simulator (FDS). A model apartment with fixed combustibles was created using FDS. The fire growth characteristics were studied and heat release rate, the rise of temperature, toxic gas dispersion and human evacuation were assessed. The fire was generated using a burner function. Computational analysis results from those models were analyzed and discussed. The relationship of wind and ventilation effect with time helps to predict the fire growth behavior in different location of the apartment. Evacuation modeling was created to illustrate the effect of evacuation time and fractional effective dose (FED) for different types of agents. FED is the summation of toxic gas consumption which is important for safe evacuation. The results show that the ventilation effect releases the heat and makes the apartment less vulnerable. Elderly people took more time for total evacuation than other groups that related to FED percentage. The idea of critical door length is demonstrated for safe evacuation during fire emergencies.
\end{abstract}

Keywords: Fire safety, Evacuation, Fire spread, FED, Fire Dynamic Simulator (FDS).

\section{Introduction}

Fire accidents have become an alarming issue in Bangladesh. Some of them were severe with massive destruction and fetal like Chawk Bazar fire and F R tower fire in Dhaka $[1,2]$. With the growing population and rapid urbanization, unplanned housing and congestion in both residential and commercial areas are increasing with accelerates the risk of fire hazard [3]. From 1 January 1997 to 31 December 2018, nearly 250,000 fire incidents took place in Bangladesh [4]. A statistical report of Bangladesh Fire Service narrated that the number of fire accidents was more than 20 thousand in 2020 and total amount of loss was around 2.4 billion Taka. The report described the total mortality in 2020 is 154 [5]. The loss from these accidents can be mitigated by predicting fire spread behavior properly which can be done by understanding the fire spread mechanism [6]. In this paper, fire spread characteristics and evacuation modeling processes are studied through a numerical CFD analysis. This process was done by using a software named Fire Dynamic Simulator (FDS). A real fire scenario can be predicted and simulated by FDS as it shows a reliable result with real cases [6-9]. Any fire growth mechanism like heat release rate, temperature, effects of burning and also evacuation modeling can be done through numerical calculation. Fire behavior prediction in buildings largely depends on properties of combustibles such as the quantity, material, surface area or composition of the combustible [10,11]. Here, a residential apartment model was designed for the analysis. Fire scenarios were studied with fire growth behavior and effects of burning like toxic gases releasing concentration like $\mathrm{CO}, \mathrm{CO}_{2}$. These gases are injurious to health and can be lethal up to a certain amount $[12,13]$. A fire spread prediction can be successfully obtained for residential buildings using their relationships with time as illustrated in Kim et al works [6]. This analysis was performed in different environments like a normal situation, unstable windy situation to predict the fire scenario in different environments. Exhaust effect was used to make this study more interesting by using a fan with constant velocity. All analysis was performed by closing the kitchen window to predict how the fire spread without a proper ventilation system. The fire was initiated in the kitchen using a propane gas burner with a soot yield of 0.1 and a $\mathrm{CO}$ yield of 0.05 . Wind flow was $5 \mathrm{~ms}^{-1}$ and mechanical fan velocity was 1.8 $\mathrm{ms}^{-1}$. FDS+EVAC is well known validated and demonstrated for evacuation modeling in case of fire accidents [14]. 


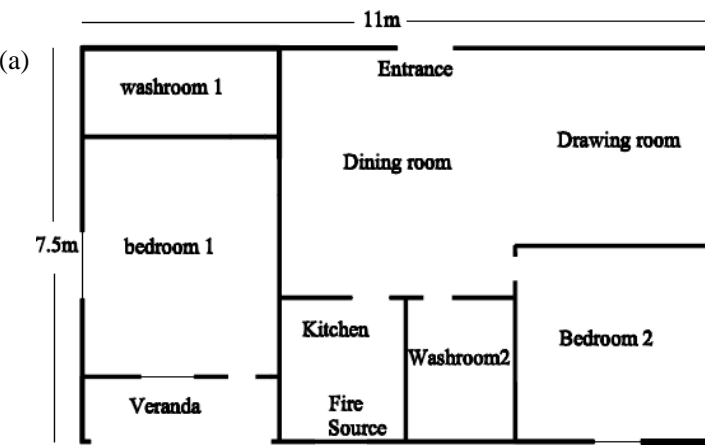

Fig. 1: Top view (a) and isometric view (b) of the model apartment
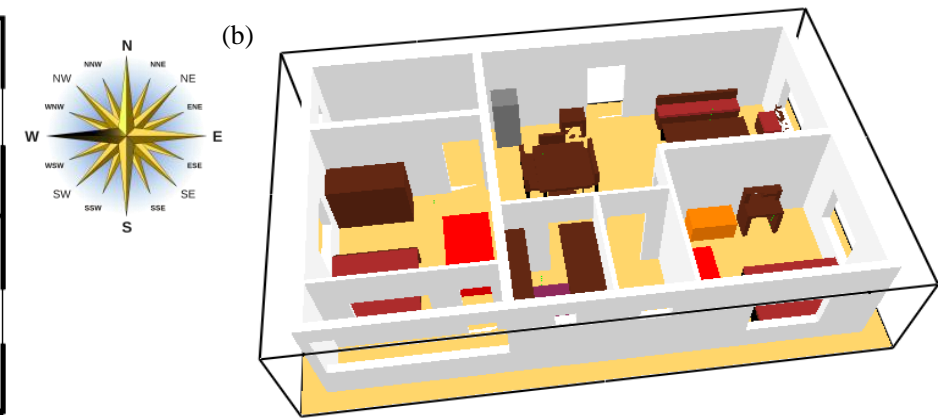

\section{Numerical Model Design and Analysis}

\subsection{Model design}

The numerical analysis was done on a model of a typical regular single apartment. The model $\left(82.5 \mathrm{~m}^{2}\right.$ area) with $11 \mathrm{~m} \times 7.5 \mathrm{~m} \times 3.048 \mathrm{~m}$ included two bedrooms, two washrooms, a kitchen, a dining room and a balcony adjacent to bedroom 1. The wall thickness is set 6 inches. An exhaust fan was placed outside wall of the kitchen. Top view and isometric view of the model is shown in Fig. 1. The dimension of different rooms is listed in Table 1.

Table 1:

Dimension of different rooms

\begin{tabular}{lccc}
\hline Room & Length $(\mathbf{m})$ & Width $(\mathbf{m})$ & Height $(\mathbf{m})$ \\
\hline Bedroom 1 & 4.1 & 3.8 & \\
Bedroom 2 & 3.8 & 3.8 & \\
Drawing & 3.8 & 3.7 & \\
Dining & 3.4 & 3.7 & \\
Kitchen & 1.8 & 2.7 & 3.05 \\
\hline
\end{tabular}

\subsection{Mesh analysis}

A uniform rectangular grid $(120 \times 85 \times 30)$ was used for calculation and they were divided into 8 meshes. The result between coarse mesh and the fine mesh has no difference. Here, the moderate mesh was used and $\mathrm{D} * / \mathrm{dx}=10 . \mathrm{D}^{*}$ is a characteristics fire diameter and $\mathrm{dx}$ is the nominal size of the mesh cell [5]. For evacuation, coarse mesh was used and $\mathrm{D}^{*} / \mathrm{dx}=4$. Mesh analysis is very important for time saving in large simulation. $\mathrm{D} * / \mathrm{dx}$ need to be definite and consistent otherwise the simulation will not run and sometimes will create inconsistent results.

\subsection{Burner and combustible load}

The fire started in the kitchen assuming a propane gas burner. The burner is producing a constant heat release rate per unit area (HRRPUA) $500 \mathrm{~kW} / \mathrm{m}^{2}$ with a $1.8 \mathrm{~m}^{2}$ area burner. The heat release rate is used by averaging the total combustible heat release rate $[6,8]$. Different combustible loads are stated in Table 2.

\subsection{Effect modeling and device parameters}

The numerical analysis was run for three types of situations: normal weather, $5 \mathrm{~ms}^{-1}$ wind flow from east to west and $5 \mathrm{~ms}^{-1}$ wind flow from west to east. An exhaust fan with velocity of $1.8 \mathrm{~ms}^{-1}$ is used to show the exhaust effect. The doors and the windows were set to open except the kitchen window. Devices to measure toxic gas flow, the volume fraction of gas and temperature were placed in each compartment. Combustibles like furniture and household products were positioned in different rooms. The wind model was created using the following numerical equation.

$$
u(z)=\frac{u *}{k} \ln \frac{z}{z_{0}}-\varphi_{m} \frac{z}{L}
$$

here, $u *$ is the friction velocity, $k=0: 41$ is the Von Kármán constant, $z_{0}$ is the aerodynamic roughness length and $\mathrm{L}$ is the Obukhov length. Obukhov length is different for different wind stability [15]. In the model Obukhov length, $L$ is -350 and aerodynamic roughness length, $z_{0}$ is 0.5 .

\subsection{Evacuation modeling}

For evacuation calculation, the statistical distribution which is used to define the characteristics of agents were taken uniform (Index 1) for all types of agents and the distribution of agent was not random [16]. Time distribution for, uniform distribution, low 
was taken as 0.5 and high was taken as 1.5 . All of their properties including body diameter and velocity were taken as default. Evacuation time and FED amount were saved in the output file.

Table 2:

Modeling of different household combustible load

\begin{tabular}{|c|c|c|c|c|c|}
\hline Combustible & Material & Weight(kg) & Combustible & Material & Weight(kg) \\
\hline Bed 1 & Wood, Foam & 40 & Shoe rack & Wood & 7 \\
\hline Bed 2 & Wood, Foam & 37 & Refrigerator & Steel & 64 \\
\hline Table 1 & Wood & 35 & Television & Plastic & 5 \\
\hline Tea table & Wood & 18 & Wardrobe & Wood & 47 \\
\hline Sofa 1 & Wood, Foam & 24 & Utensil's bindings & Plastic, Wood & 14 \\
\hline Sofa 2 & Wood, Foam & 9 & Six Chairs & Wood & 48 \\
\hline Sofa 3 & Wood, Foam & 9 & Wood plank & Wood & 10 \\
\hline Reading table & Wood & 16 & Shoe rack & Wood & 7 \\
\hline
\end{tabular}

(a)

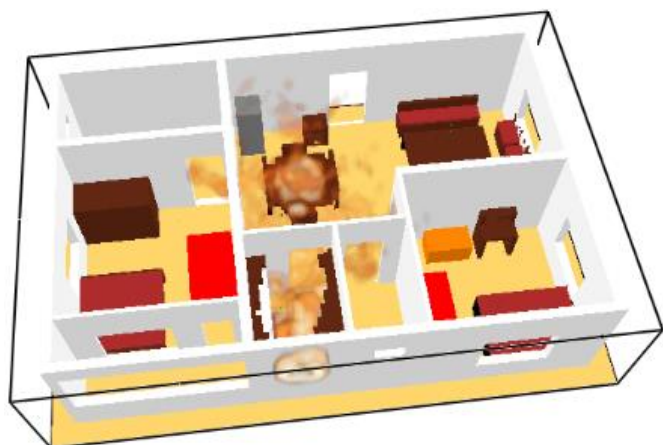

(c)

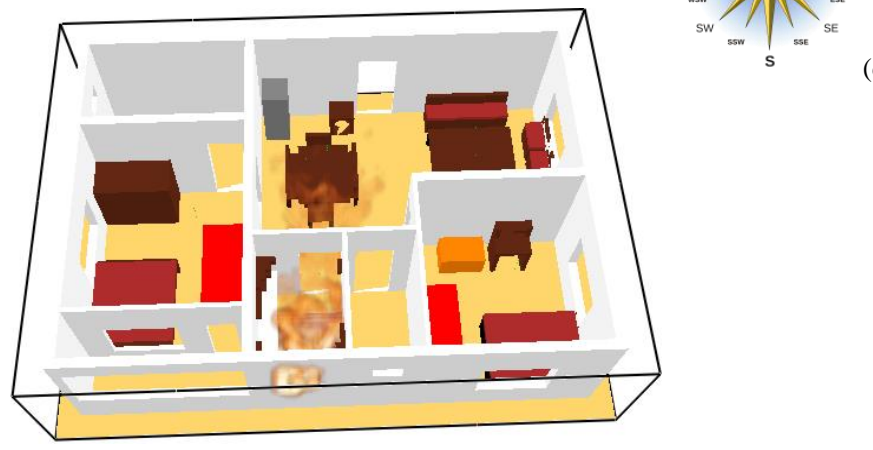

(b)

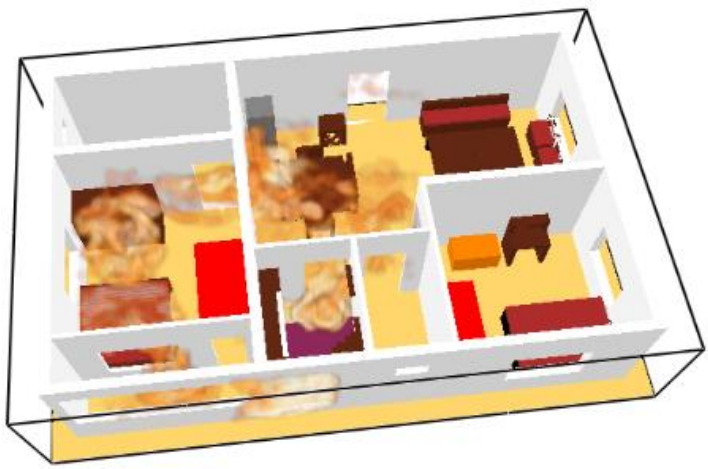

(d)

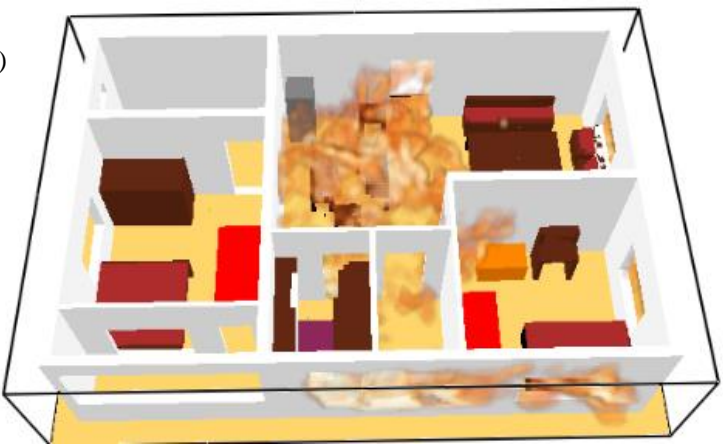

Fig. 2: Fire scenario in different situation (a) Normal, (b) Wind E to W, (c) Wind W to E and (d) Exhaust at 150 sec.

\section{Results and Discussion}

All numerical analysis was done by closing natural ventilation in the kitchen (window). The heat release rate was constant. Smoke covered the kitchen, dining and drawing room at 9 seconds and the whole - apartment at 56 seconds fully in normal effect. With artificial ventilation effect, smoke covered the whole apartment at 64 seconds fully. In the normal situation, the dining table was fired at 175 seconds and fully burned away at 278 seconds. But there was no sign of fire in the dining table in exhaust effect. Wind flow 
shows a drastic change in the fire scenario comparing with the normal effect. Wind from east to west drove the fire to burn the dining table at 160 seconds but the table was not burned fully. But the wind from west to east pushed the fire to burn the table at 124 seconds and the fire burnt the whole dining table with chair, drawing tea table and sofa's foam fully at 310 seconds. A visual observation of fire scenario is shown in Fig. 2 for different situations at $150 \mathrm{sec}$ of the simulation. Wind direction shows the change in fire growth pattern. Room at west side were burned only when the wind was in $\mathrm{E}$ to $\mathrm{W}$. The heat release rate has differed in different scenarios and wind direction as shown in Fig. 3.

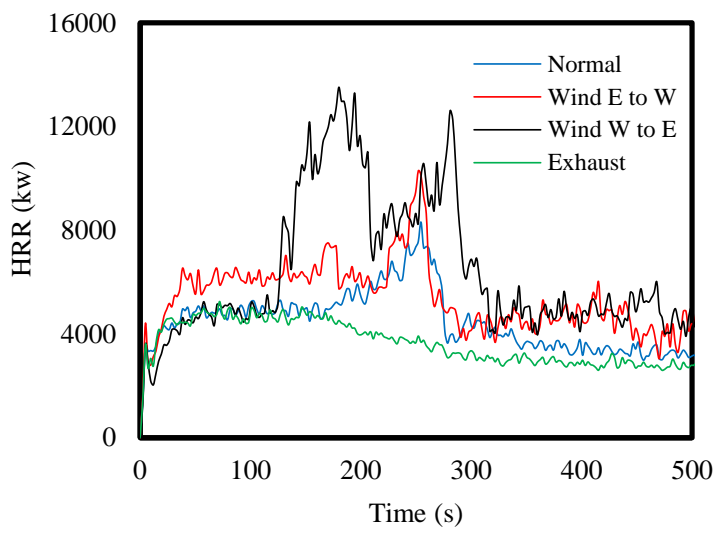

Fig. 3: Heat release rate vs time at the different situations

Sudden change of the heat release rate at the initial stage of time represents the constant heat release rate producing burner. When wind flowed from west to east, heat release rate increased rapidly comparing with others having the highest rate of $13515 \mathrm{~kW}$. It dictates a large number of combustible burnings in dining and drawing. Fire acts like a fluid system in which direction depends on the driving force of the air. Most of the combustibles were in the dining and drawing-room.

From Fig.1 we can see that the position of the dining and drawing-room is in the east. So, wind from west to east created a dramatic change in heat release rate as most of the combustibles burned away fully. It is seen that the temperature first decreases at 190 seconds and again it increases in the kitchen when wind flows from west to east. Bedroom 1 and bedroom 2 was not heated due to the flow of wind in a different direction. So, that's are not shown in the graph. We can get an idea of flashover from these graphs. Flashover is an important phenomenon in a fire. When a combustible gets into the flashover period, it cannot be saved from the fire. The peak value of temperature indicates the flashover point. Flashover happened in dining around 230 seconds and in drawing at 240 seconds at normal effect. At the wind $\mathrm{W}$ to $\mathrm{E}$ effect, flashover happened in dining, drawing and bedroom 2 around 140 seconds.
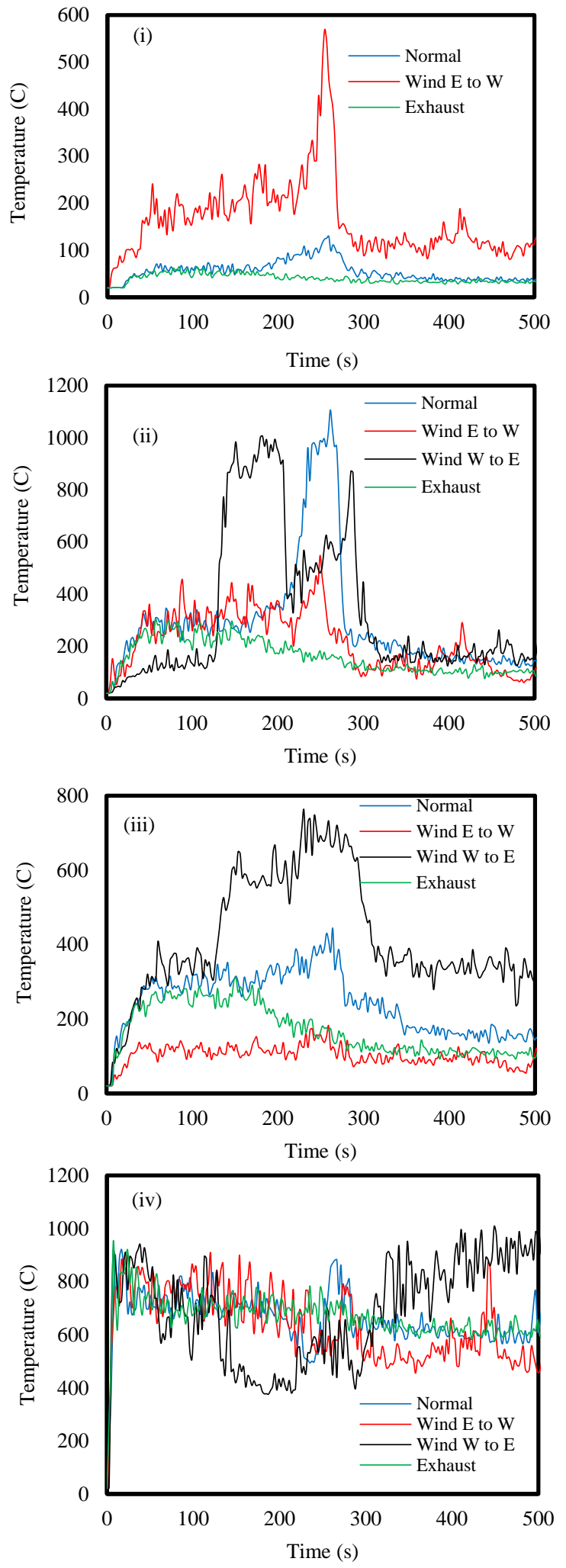

Fig. 4a: Temperature vs time at different situations - (i) bedroom 1, (ii) dining, (iii) drawing and (iv) kitchen 


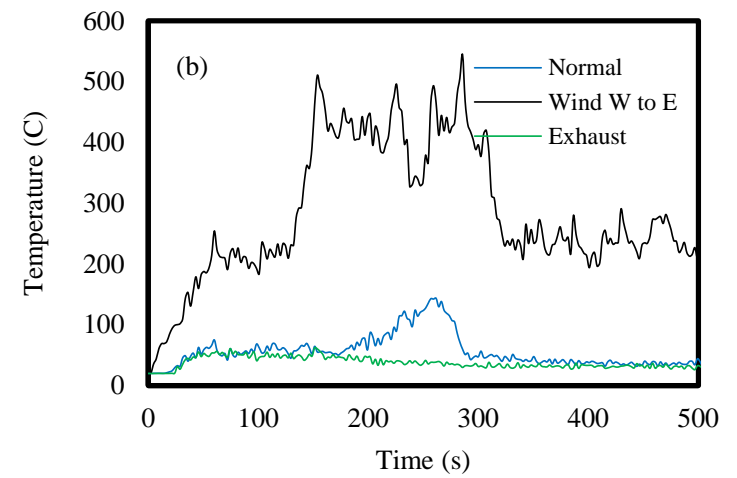

Fig. 4b: Temperature vs time for bedroom-2.

In bedroom 1, there was a sudden jump of temperature when wind flowed from east to west due to unstable wind. Sometimes, the main power switch cannot be turned off timely in a fire situation because most of the houses are not automated with a fire system in Bangladesh. Mechanical ventilation is used in the kitchen for removing smoke and toxic gas produced from fuel burning. Here is shown a ventilation effect in Fig. 4a (i-iv) and Fig. 4b. When the ventilation was switched on, the fire could not spread in the house. We can get the idea from the temperature graph. Mechanical ventilation draws out the air from inside and throws away outside. That was the reason for not building up the temperature.

The carbon monoxide (CO) concentration vs time graph in different location of the apartment is shown in Fig. 5 (a-e).
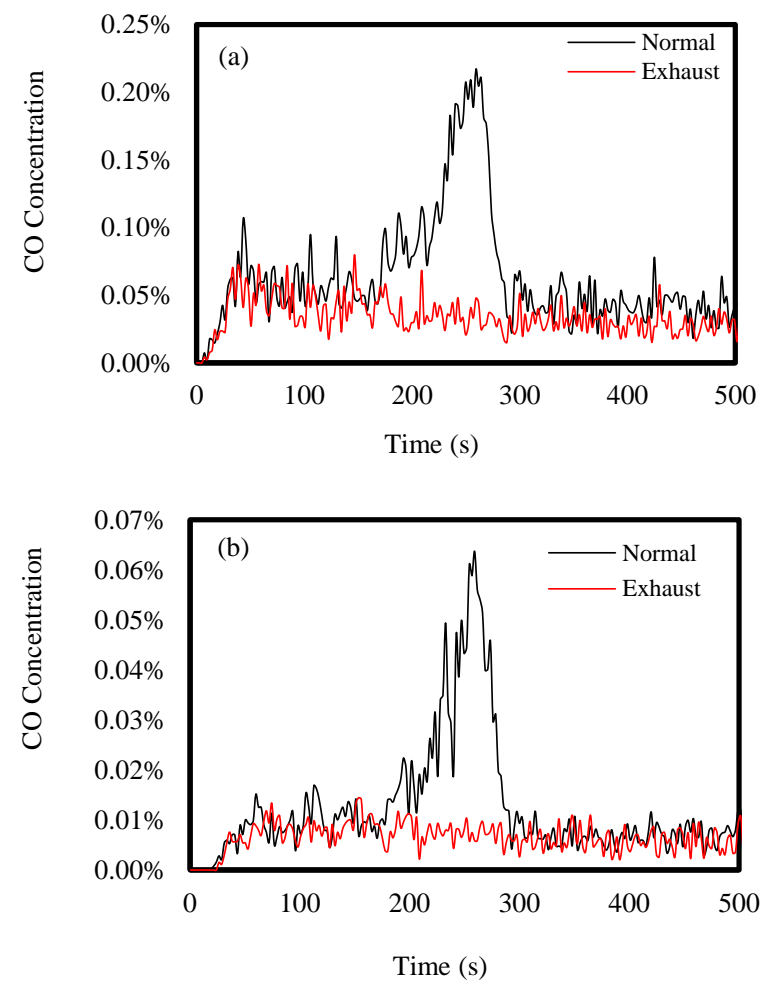
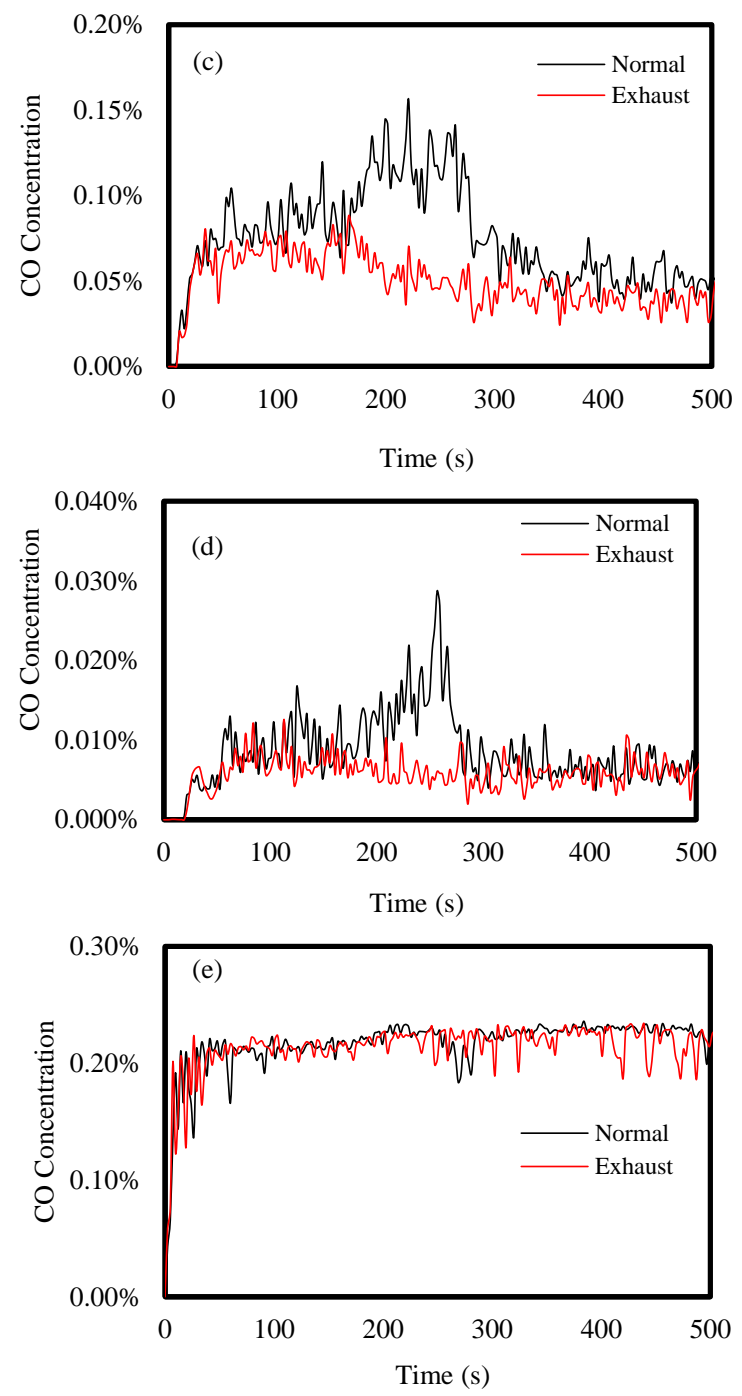

Fig. 5: CO concentration vs time at different location of the apartment - (a) bedroom 1, (b) bedroom 2 (c) dining, (d) drawing room and (e) kitchen

There is a sudden jump of $\mathrm{CO}$ concentration at normal effect around 255-260 seconds in bedroom 1 and bedroom 2 as shown in Fig $5(a, b)$. Due to flashover, huge CO build-up at 210-280 seconds in the dining and drawing-room. An exhaust fan creates a drastic change in building up of CO. It shows the effect of ventilation in a fire. For the exhaust system with 1.8 $\mathrm{ms}^{-1}$ velocity speed, toxic gas couldn't develop in all rooms. It also helped to reduce concentration in the kitchen. Toxic gas concentration in the mole fraction percentage was constant for all rooms. In the kitchen, there is a sudden increase in temperature and gas concentration dictates the constant heat-releasing rate from the propane gas burner. Toxic gas like $\mathrm{CO}$ and $\mathrm{CO}_{2}$ are produced from burning. But our focus was mainly on carbon monoxide. $\mathrm{CO}$ formation is 
proportional to the amount of burning. That is why both the temperature graph and $\mathrm{CO}$ concentration graph quite similar.
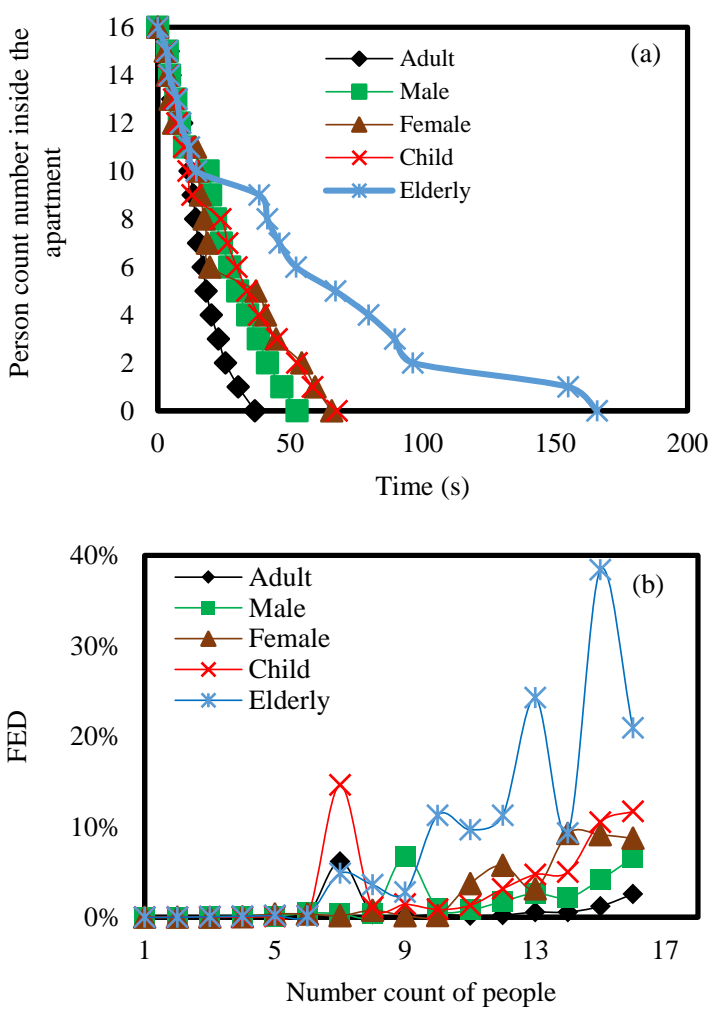

Fig. 6. Comparison of (a) evacuation time and (b) FED percentage between different groups of people

Evacuation calculation is needed for every structural design. Safety is the first requirement in every project. In this numerical analysis, safe evacuation time and fractional effective dose (FED) were calculated for different groups of people. These were done in normal effect. In FDS+EVAC, there are 5 types of default agents. They are adult, male, female, child and elderly. The adult is the combination of the diameter and velocity of both males and females. All parameters for these different types of agents were taken as default values. The comparison of evacuation time for different groups of agents are shown in Fig. 6(a). Total 16 agents were used and placed randomly in the apartment. It is seen that adult agents took less time and the last adult came out from the house at 36.64 seconds. For male agents, the total safe evacuation was done at 52.57 seconds. Females and children took almost the same time for total evacuation. But female agents took less time than a child when 8 to 6 females were inside. Females took 65.65 seconds and children took 67.59 seconds for total evacuation. Elderly agents took much time for evacuation and the last two-person took more time than other elderly people. They took 165.87 for evacuation. The first five agents of all groups took almost the same time in evacuation as shown in the figure. Fractional effective dose (FED) taken by every agent is also shown in Fig. 6(b) for different groups. FED is very much important in burning buildings and high-rise structures. Because it is the total amount of carbon monoxide (CO) and carbon dioxide $\left(\mathrm{CO}_{2}\right)$ taken by a person in the evacuation process. In the figure, the FED percentage is shown for each agent. It is seen that the first six agents of all groups took the same amount of FED. Number 7 agent of child and adult took the maximum amount of FED in their group and that amount was $14.62 \%$ and $6.16 \%$. Male number 9 agent took the maximum from their group and the percentage is 6.72 . The first 10 females took below 1\% FED and the highest amount was $9.26 \%$ which was taken by the $14^{\text {th }}$ number agent. As elderly people took more time than any other group for total evacuation, they took much FED than any other group. FED is mainly depending on the concentration of $\mathrm{CO}, \mathrm{CO}_{2}$ and $\mathrm{O}_{2}$ and the amount of time in the evacuation process. The $15^{\text {th }}$ number agent of the elderly group took the maximum amount of percentage with the number of $38.40 \%$. From the FED calculation, we can see that children and elderly people were affected by toxic gas more than any other group in the same amount of time. A little increase in carbon monoxide and carbon dioxide can be dangerous and creates the death possibility. For these calculations, the length of the exit door was $0.75 \mathrm{~m}$. Evacuation time depends on many other things like agents' position, structure design, exit door area etc.

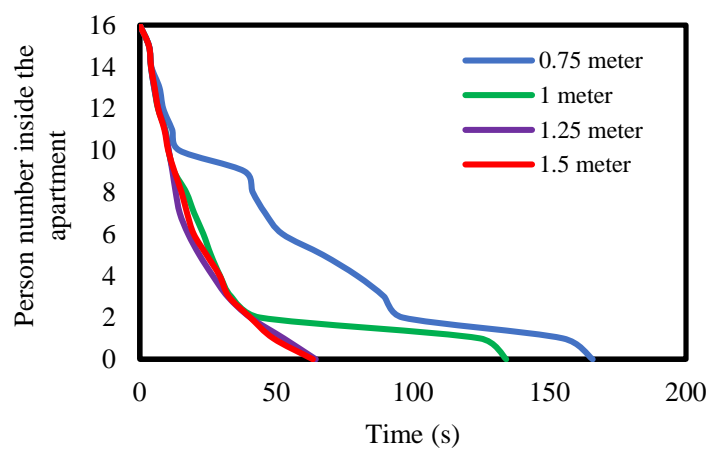

Fig. 7: Exit door length effect on evacuation time for elderly

The exit door length effect in evacuation for elderly people is shown in Fig. 7. Elderly people took more time than any other groups, so they were chosen in the simulation to visualize the door area effect. Every time the width and height of the door were fixed and the length was varied with around fixed position agents. From the figure, we can see that the first 6 agents took almost the same time for evacuation for different 
lengths. For 1.25 meters and 1.5 meters the evacuation time curve is almost the same which indicates the same time variation. For 0.75 meter and 1 meter, the last two agents took much time than the other agents. It creates a critical door length idea. Critical door length is the minimum length of the exit door where people can get evacuated easily. Though the exact critical door length was not calculated in the simulation, we can get an idea from this graph. The total evacuation time for 1 meter, 1.25 meters and 1.5 meters are 134.22 seconds, 64.51 seconds and 63.42 seconds respectively.

\section{Conclusion}

Simulation results of fire growth behavior for a typical residential apartment are discussed in this paper. Introduction of a mechanical exhaust fan in kitchen has significantly reduced the fire impact inside the apartment. So introduction of proper ventilation and exhaust system may help in avoiding flashover situation by releasing excess heat that trapped inside the house during the fire. The significant temperature rises and toxic gas formation due to flashover scenarios were seen in case of natural ventilation and wind effect. Toxic gas concentration and FED values in this study can forecast the time required for safe evacuation in case accidental fire. Critical door length is very much important in structure fire safety design. The elderly and children were found more vulnerable during evacuation. Fire studies with numerical analysis have not only become reliable but also costfriendly regarding real fire test costs. So, numerical simulation of fire growth study can help in understanding the fire impacts and in designing suitable fire protection equipment for residential apartment.

\section{References}

[1] Safi, Michael (21 February 2019). "Dhaka fire that killed 80 raises questions over chemical stores". The Guardian [accessed 26 November 2019] Available: https://www.theguardian.com/world/2019/feb/21/dhak a-fire-more-than-50-die-in-apartments-used-aschemical-store.

[2] Julfikar Ali Manik (28 February 2019). "At Least 25 Die in Office Tower Fire in Dhaka, Bangladesh". The New York Times [accessed 26 November 2019] Available: https:// www. nytimes. com /2019 /03/28/ world/asia/ bangladesh-fire-dhaka.html.
[3] Opie, K., March, A., Leonard, J. and Newnham, G. (2014). Indicators of Fire Vulnerability: Risk Factors in Victorian Settlements.

[4] Jahangir, A.R., 2019, 'Fire incidents in Bangladesh triple in 22 years', UNB, viewed 1 September 2019 from, https://unb.com.bd/category/Special/fire-incidents-inbangladesh triple-in-22-years/13435

[5] Bangladesh Fire Service and Civil Defense Department Annual Statistical Data 2020: p. 2-4.

[6] Ahn, C. S.; Kim, J. Y. A Study for a Fire Spread Mechanism of Residential Buildings with Numerical Modeling. WIT Trans. Built Environ. 2011, 117, 185196. https://doi.org/10.2495/SAFE110171.

[7] McGrattan, K., Hostikka, S., McDermott, R., Floyd, J., Weinschenk, C., \& Overholt, K. (2015). Sixth edition fire dynamics simulator technical reference guide volume 1: mathematical model. NIST Special Publication 1018, $1 . \quad$ pp: $31-44$ https://doi.org/10.6028/NIST.SP.1018-1

[8] Hadjisophocleous, G.; Zalok, E. Development of Design Fires for Performance-Based Fire Safety Designs. Fire $\begin{array}{lll}\text { Saf. } & \text { Sci. } & \text { 63-78. }\end{array}$ https://doi.org/10.3801/IAFSS.FSS.9-63.

[9] Blake, P., Andrews, G., Yorkshire, W., \& Kingdom, U. (n.d.). Validating fds against a full-scale fire test.

[10] Ronchi, E., Testing the predictive capabilities of evacuation models for tunnel fire safety analysis. Safety Science, 2013. 59(Supplement C): p. 141-153.

[11] Seo, D., et al., An Experimental Study on the Combustibles Investigation and Fire Growth Rate for Predicting Initial Fire Behavior in Building. Procedia Engineering, 2013. 62 (Supplement C): p. 671-679.

[12] Purser, D. Modelling Toxic and Physical Hazard in Fire. Fire Saf. Sci. 1989, 2, 391-400. https://doi.org/10.3801/iafss.fss.2-391.

[13] Hartzell, G. E.; Emmons, H. W. The Fractional Effective Dose Model for Assessment of Toxic Hazards in Fires. J. Fire Sci. 1988, 6 (5), 56-362. https://doi.org/10.1177/073490418800600504.

[14] Khan, E. A.; Ahmed, M. A.; Khan, E. H.; Majumder, S. C. Fire Emergency Evacuation Simulation of a shopping mall Using Fire Dynamic Simulator (FDS). $J$. Chem. Eng. 2017, $30 \quad$ (1), 32-36. https://doi.org/10.3329/jce.v30i1.34795.

[15] McGrattan, K., Hostikka, S., McDermott, R., Floyd, J., Weinschenk, C., \& Overhold, K. (2016). Sixth Edition Fire Dynamics Simulator User 's Guide (FDS). NIST Special Publication 1019, Sixth Edit. pp: 211-213

[16] Korhonen, T.; Hostikka, S. Fire Dynamics Simulator with Evacuation FDS+ Evac (Version 5) Technical Reference and User's Guide; 2008. pp: 78-84

(C)Bangladesh Uni. of Engg. \& Tech. 